\title{
Mechanical Behavior of Epoxy Nano composites
}

\author{
Tamer S. Mahmoud ${ }^{1}$, Ahmed I. A. Ali $^{2}$ Samah S. Mohamed $^{3}$ and, Mohamed F. S. Faramawy ${ }^{4}$ \\ 1- Prof., Faculty of Engineering, Benha University, Egypt. \\ 2- Ass. Prof., Faculty of Industrial Education, Helwan University, Egypt. \\ 3- Ass. Prof, Faculty of Engineering, Benha University, Egypt. \\ 4- Teacher in the Industrial Secondary Education, Menoufia, Egypt.
}

\begin{abstract}
In aerospace applications research efforts are focusing on the design of advanced composite materials reinforced with nano fillers. Such advanced materials combine weight saving with multifunctional properties, including mechanical. In the present investigation, multiwall carbon nanotubes (MWCNTs) nanoparticles were dispersed individually by different size percentages into epoxy-based polymeric nano composites. MWCNTs of 20 and $30 \mathrm{~nm}$ inner and outer diameters were reinforced with contents of $0.3,0.6$, and $0.9 \%$ into epoxy matrix. Mechanical properties of Epoxy/MWCNTs such as tensile strength, strain at break, impact energy, and Vickers micro hardness .The design was done using design of experiments (DOE) using mixed full .The mechanical results revealed declining in tensile strength, strain at break and impact energy. While the micro hardness values enhanced with addition of nano fillers into the epoxy matrix. Frequency response and shock absorption ratios have been severely affected by increasing ratios of nanometer materials. Where the results of mechanical tests showed a decrease in the rate of shock absorption. It is noticeable that the damping factor follows the same trend as the mechanical properties of epoxy nanoparticles.
\end{abstract}

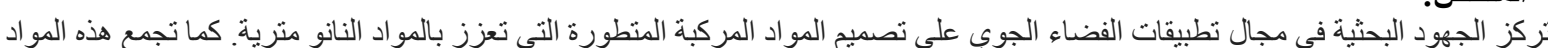

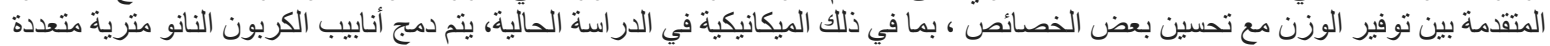

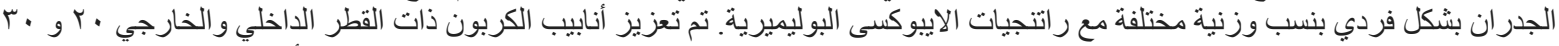

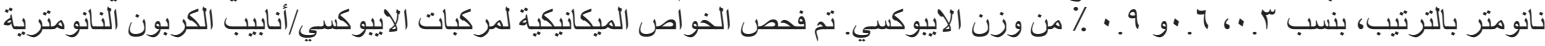

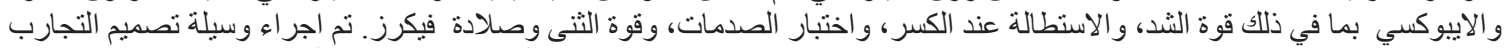

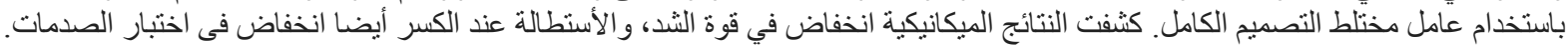

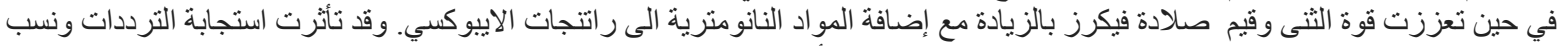

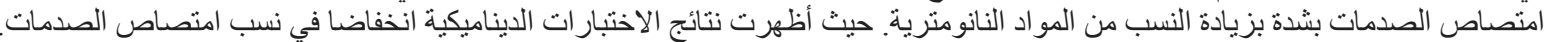

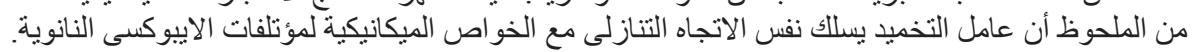

\section{1- INTRODUCTION}

In the recent years, there is a great need for composites because the combination of two or more materials can lead to enhance performance and outstanding properties compared to their constituents. Especially, the polymer based composites reinforced with a small percentage of strong fillers can significantly improve the mechanical, thermal and barrier properties of the pure polymer. Moreover, these improvements are achieved through conventional processing techniques without any detrimental effects on processability, appearance, density and aging performance of the matrix. The realization of their unique properties, has been considering for a wide range of applications including packaging, coating, sport, electronics, aerospace industries, aircraft and military, automotive, and marine engineering [1]. One part of composite material for technical applications may be represented by a thermosetting polymer matrix, e.g. an epoxy resin, which already covers alone some of the demanded properties [2]. Epoxy resins (EP) have been widely used in practical applications such as adhesives, construction materials, composites, laminates and coatings owing to their excellent mechanical properties, low cost, ease of processing, good adhesion to many substrates, and good chemical resistance [3]. However, because the polymer matrix must withstand high mechanical and tribological loads, it is usually 
reinforced with fillers. These fillers can be chosen as fibres (glass, carbon and aramid) or particles such as ceramic powders [2].

Nanoparticles have been used as fillers in polymeric composites for improving the mechanical performance of the materials. One of the distinct advantages of nanocomposites over microcomposites lies in that the performance improvement is often acquired at relatively low concentration of the nano-fillers. This is beneficial to the mechanical properties, processability and aesthetic appearance of the end-products [4]. Carbon nanotubes (CNTs) are increasingly attracting scientific and industrial interest by virtue of their outstanding characteristics. The CNT walls resemble rolled-up graphite-like sheets. According to their graphitic structure, CNTs possess high thermal conductivity and an electrical conductivity that can be either semi-conducting or metal like [3]. Ceramicpolymer composites are functional materials of a great potential for industrial applications. These composite materials combine hardness, stiffness and wear resistance of ceramics and elasticity of polymer [5,6]. The aim of the present work is to study the mechanical performance of epoxy based composites reinforced with MWCNTs. The variation of hardness, impact energy and as a function of the content of the aforementioned nanofillers was evaluated.

\section{2- Experimental Study:}

\subsection{MATERIALS}

\subsubsection{Polymer Matrix}

The type of epoxy resin used in the present investigation is KEMAPOXY-150 manufactured by Chemicals for Modern Buildings Company (CMB), Egypt. Epoxy resin is a thermoses resin with good thermal and environmental stability. The general chemical formula of the epoxy mer is shown in Fig. 2.1 .

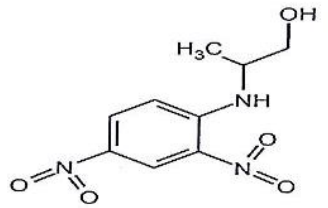

Figure 2.1. Chemical formula of epoxy matrix [7]

\subsubsection{Nanofillers}

nanofillers are MWCNTs provided as a dry powder from Nano Tech company. Multiwall carbon nanotubes (MWCNTs) were used as a reinforcing agent. MWCNTs were produced by a fully automatic system using arc-discharge technique using multi electrodes, carbon nanotubes (CNT) with a diameter of $10-40 \mathrm{~nm}$ and a length up to 5 microns as shown in Fig. 2.2. Nano-composites based on epoxy matrix containing $0.3 \%, 0.6 \%$ and $0.9 \%$ by volume of the MWCNTs were produced.

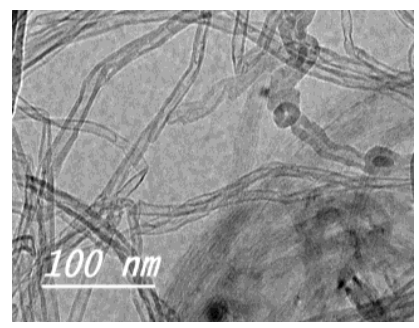

Fig. 2.2. TEM micrographs of MWCNTs.

Table 2.1. Properties of MWCNTs used in the present study [8].

\begin{tabular}{|r|r|r|r|r|r|}
\hline Property & $\begin{array}{r}\text { Density } \\
\mathrm{g} / \mathrm{cm}^{3}\end{array}$ & $\begin{array}{r}\mathrm{E} \\
(\mathrm{TPa})\end{array}$ & $\begin{array}{r}\text { Strength } \\
(\mathrm{GPa})\end{array}$ & $\begin{array}{r}\text { Thermal } \\
\text { conductiv } \\
\text { ity } \\
(\mathrm{W} / \mathrm{m} . \mathrm{k})\end{array}$ & $\begin{array}{r}\text { Electrical } \\
\text { conductiv } \\
\text { ity } \\
(\mathrm{S} / \mathrm{m})\end{array}$ \\
\hline MWCNTs & 2.6 & 1 & $6-30$ & $>3000$ & $10^{4}-10^{7}$ \\
\hline
\end{tabular}

\subsection{NANOCOMPOSITE PREPARATION}

The Epoxy/MWCNTs composites were prepared using the following technique:

1. The epoxy resin and a certain volume fraction $(0.0 .3,0.6$ and 0.9 vol.\%) of MWCNTs reinforcements were mixed together in glass 
beakers, and stirred mechanically at $300 \mathrm{rev} / \mathrm{min}$. for more than 20 minutes at room temperature;

2. The hardener was added to the mixture by the ratio $1: 2$ by volume and then stirred mechanically again for three minutes;

3. The epoxy/MWCNTs slurry was poured in a plastic dies;

4. Finally, the mixture was allowed to fully harden at room temperature.

Figure 2.3 shows a schematic illustration of the preparation technique used for manufacture Epoxy/MWCNTs composites. The unreinforced epoxy matrix samples were prepared using the same technique described above but without any addition of MWCNTs.

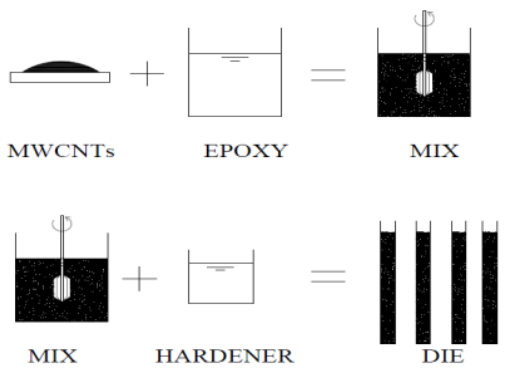

Fig. 2.3. A schematic illustration showing the epoxy/ MWCNTs composites preparation technique.

\section{Tensile Test}

Tensile tests of the nanocomposites were performed according to ASTM D 638-03 standard (Standard Test Method for Tensile Properties of Plastics), using the (Instron) universal testing machine with a load cell of $5 \mathrm{KN}$ and a constant speed of 10 $\mathrm{mm} / \mathrm{min}$. Three specimens for each condition were tested. The load displacement results were analyzed to calculate the tensile strength of nanocomposite specimens.

The results are illustrated in the form of load vs displacement curve as shown in Fig.2.4. for Epoxy/0.3 vol. \% MWCNTs nanocomposites specimen.

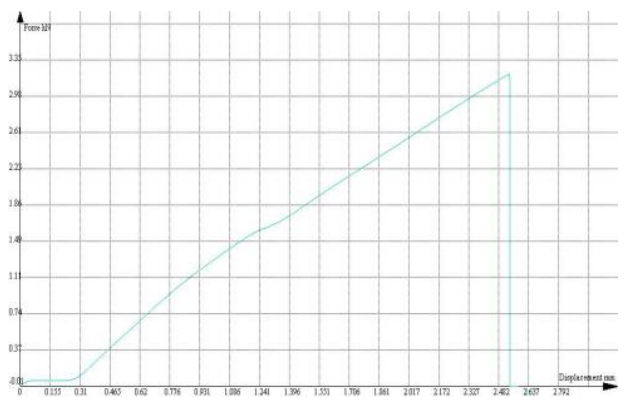

Figure 2.4. Load vs displacement relation for the tensile test of Epoxy/0.3 vol. \% MWCNTs nanocomposites

\subsubsection{Impact Test}

Charpy impact test was performed according to DIN-ISO179. The impact strength of the composites was measured using notched specimen with rectangular dimensions of $80 \times 10 \times 4 \mathrm{~mm} 3$ as shown in Fig.2.5. Charpy impact strength-testing machine (HIT 50P Zwick/Roell) was used with a pendulum energy 0.5 Joule, angle of inclination (fall angle) 106.380 at room temperature as illustrated in Fig.2.6. The distance between the supports (span distance) was set to $60 \mathrm{~mm}$. three specimens of each condition were tested and the average values of the data are reported.

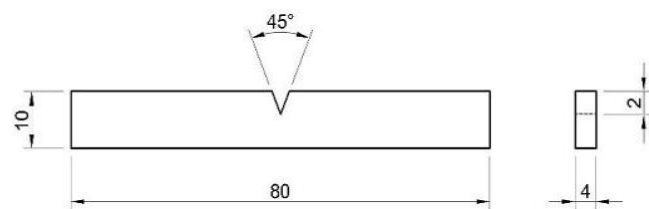

Fig.2.5. Schematic illustration of the impact specimen

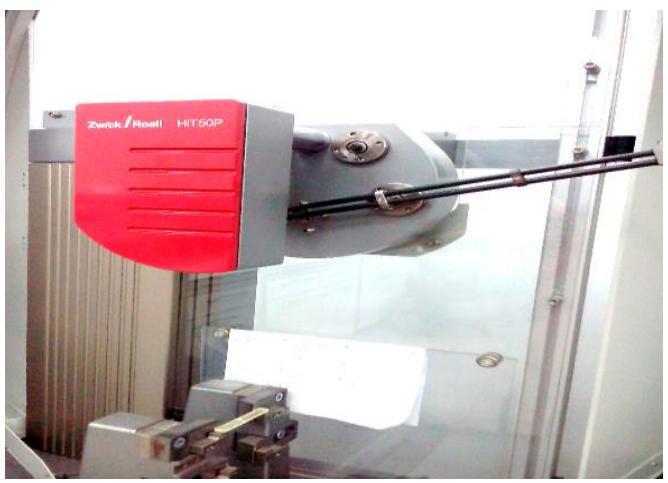

Figure 2.6. Charpy impact test machine 


\section{3- Results and Discussions:}

\subsubsection{Microhardness Properties}

The average Vickers microhardness results are illustrated in Table 3.1. The microhardness values increase with addition of more volume percentage of the MWCNTs nanofiller. The variation of the average Vickers microhardness of the nanocomposites with the nanofillers contents is illustrated in Fig.3.1. The Epoxy/ MWCNTs nanocomposites showed slightly high average microhardness values than the neat epoxy matrix. The maximum value of the microhardness is about $18 \mathrm{VHN}$ was observed for Epoxy /0.6 vol. \% MWCNTs nanocomposites. Moreover, the increasing of nanoparticle content in the matrix, decreases the inter particle distance which caused increase of resistance to indentation [9].

Table 3.1 Microhardness of epoxy nano composites

\begin{tabular}{|l|l|l|}
\hline Composite type & $\begin{array}{l}\text { Ultimate } \\
\text { tensile } \\
\text { strength } \\
(\mathrm{MPa})\end{array}$ & $\begin{array}{l}\text { Strain at } \\
\text { break (\%) }\end{array}$ \\
\hline Neat epoxy & 42.8 & 6.4 \\
\hline $\begin{array}{l}\text { Epoxy/0.3 vol.\% } \\
\text { MWCNTs }\end{array}$ & 38.2 & 5 \\
\hline $\begin{array}{l}\text { Epoxy/0.6 vol. \% } \\
\text { MWCNTs }\end{array}$ & 37.5 & 4.4 \\
\hline $\begin{array}{l}\text { Epoxy/0.9 vol. \% } \\
\text { MWCNTs }\end{array}$ & 27.6 & 2.4 \\
\hline
\end{tabular}

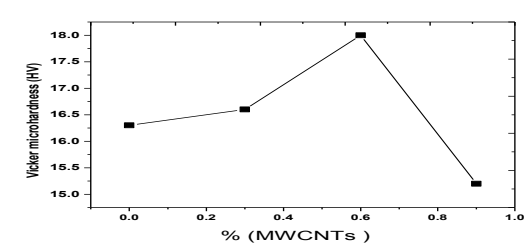

Figure 3.1 Micro-Hardness values for Epoxy/MWCNTs nanocomposites

\subsubsection{Tensile Strength}

Table 4.2 shows the tensile properties of Epoxy/MWCNTs nano composites. The tabulated results show a reduction in ultimate tensile strength when adding the nanofillers into the epoxy matrix. The strain at break have the same down trend with the tensile strength. Figure 3.2. shows the tensile results of the neat epoxy and the two nanocomposites. Generally, the results revealed that dispersion of MWCNTs nanoparticles tend to reduce the ultimate tensile strength of the nanocomposites. The

Table 3.2 Tensile properties of epoxy nano composites

\begin{tabular}{|r|r|r|r|r|}
\hline $\begin{array}{r}\text { Nano } \\
\text { fillers wt. } \\
\%\end{array}$ & 0 vol. \% & 0.3 vol. \% & 0.6 vol. \% & 0.9 vol. \% \\
\hline $\begin{array}{r}\text { Ep/MWC } \\
\text { NTs }\end{array}$ & $16.3 \pm 0.5$ & $16.6 \pm 0.4$ & $18 \pm 0.8$ & $15.2 \pm 0.7$ \\
\hline
\end{tabular}

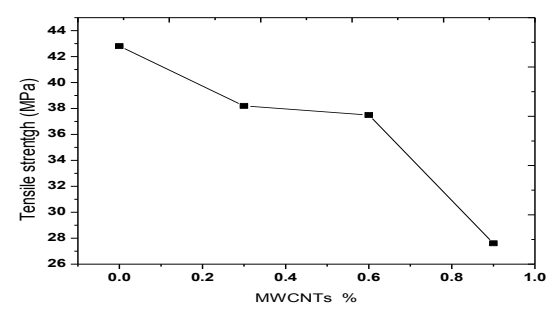

Figure 3.2. Variation of tensile strength vs nanofillers vol. \% for Epoxy/MWCNTs nanocomposites

The reduction in tensile strength and the enhancement in microhardness of the epoxy when imbedded by MWCNTs nanofillers can be analyze as follows: when a tensile load acts on the nanocomposites; the filler matrix bond become weak, this may cause a fracture in the nanocomposites. However, in the hardness case, when a compression stress take place, the two phases (matrix and the nanofillers) being pressed together and they tightly connected with each other. Consequently, pressure can effectively transfer and the microhardness may be improved [10].

Figure 3.3. shows that the strain at break was declined with the nanofillers addition. Little reduction in breaking strain was observed for Epoxy/MWCNTs nanocomposites with the increasing content of MWCNTs in the nanocomposite as seen in Fig.3.3. The reduction in strain might be due to incorporation of rigid nanofillers into a polymeric matrix; this indicates the brittle behaviour of the nanocomposites 
due the formation of nano defect results in regional stress concentration in the matrix. The brittleness of the nanocomposites might be caused by these voids and defects [11]. This brittle behaviour of the nanocomposites caused high declining of the strain values of the neat epoxy when imbedded by 0.3 vol. $\%$ of the nanofillers.

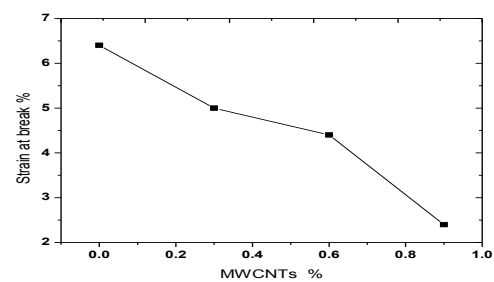

Figure 3.3. Strain at break for Epoxy/MWCNTs nano composites

\section{Conclusions:}

Based on the results acquired from the present investigation, the following conclusions can be investigated:

1- The Epoxy/MWCNTs nanocomposites exhibited lower ultimate tensile strength when compared with pure epoxy matrix

2- The Epoxy/MWCNTs nanocomposites showed slightly higher average microhardness than the pure epoxy matrix.

3- Addition of MWCNTs into the epoxy matrix leads to reduce the impact energy of the nanocomposites.

\section{References:}

[1] M. M. Sakka, Z. Antar, K. Elleuch, J. F. Feller, "Tribological response of an epoxy matrix filled with graphite and/or carbon nanotubes", 5(2), 2017, pp. 171-182.

[2] Haiyan Chen, Olaf Jacobs, Wei Wu, Gerrit Rudiger, Birgit Schadel, "Effect of dispersion method on tribological properties of carbon nanotube reinforced epoxy resin composites", Polymer Testing, 26, 2007, pp. 351-360.

[3] Qunfeng Cheng, Jiaping Wang, Kaili Jiang, Qunqing Li, Shoushan Fan, "Fabrication and properties of aligned multiwalled carbon nanotube-reinforced epoxy composites", July 2008.

[4] Behrouz Arash, S. Harold Park, Timon Rabczuk, "Mechanical properties of carbon nanotube reinforced polymer nanocomposites: a coarsegrained model", Applied physics, Composite Part, 2017.

[5] Bernd Wetzel, Frank Haupert, Ming Qiu Zhang, "Epoxy nanocomposites with high mechanical and tribological performance", Composites Science and Technology 63, 2003, pp. 2055-2067.

[6] Yang Lia, Liubing Dongb, Xiang Zhanga, Yinghua Lua, Weiping Fanga, Yiquan Yanga, "Preparation of carbon nanotubes/epoxy composites using novel aerogel substrates", Materials letter, 175, 2015, pp. 1-9.

[7] Ishida H., "Polymer Composite", Handbook, 1996

[8] Mantena, Keerthi Varma, "Electrical and mechanical properties of MWCNT filled conductive adhesives on lead free surface finished PCB's.", University of Kentucky Master's Theses, 613,2009 .

[9] K. Devendra, T. Rangaswamy, "Strength Characterization of E-glass Fiber Reinforced Epoxy Composites with Filler Materials", Journal of Minerals and Materials Characterization and Engineering, 1, 2013, pp. 353-357.

[10] Shodhganga, "Mechanical and Tribological Properties of Epoxy Nanocomposites, CH. 7, pp. 173-174.

[11] W. Li, A. Dichiara, J. Bai, "Carbon nanotubegraphene nanoplatelet hybrids as highperformance multifunctional reinforcements in epoxy composites", Compos. Sci. Technol., 74, 2013, pp. 221-227. 